\title{
DNA methyltransferase 1-targeting miRNA-148a of dairy milk: a potential bioactive modifier of the human epigenome
}

\begin{abstract}
Bodo C. Melnik ${ }^{1 *}$ and Gerd Schmitz ${ }^{2}$
${ }^{1}$ Department of Dermatology, Environmental Medicine and Health Theory, University of Osnabrück, Osnabrück, D-49076, Germany, ${ }^{2}$ Institute for Clinical Chemistry and Laboratory Medicine, University Hospital Regensburg, University of Regensburg, D-93053 Regensburg, Germany
\end{abstract}

*Corresponding Author: Bodo C. Melnik, MD, Department of Dermatology, Environmental Medicine and Health Theory, University of Osnabrück, Osnabrück, D-49076, Germany

Submission Date: July 30, 2017, Acceptance Date: September 26, 2017, Publication Date: September 30, 2017

Citation: Melnik B.C., Schmitz G., DNA methyltransferase 1-targeting miRNA-148a of dairy milk: a potential bioactive modifier of the human epigenome. Functional Foods in Health and Disease 2017; 7(9); 671-687. https://doi.org/10.31989/ffhd.v7i9.379

\begin{abstract}
:
Background: The perception of milk has changed from a "simple food" to a more sophisticated bioactive functional signaling system that promotes mTORC1-driven postnatal anabolism, growth, and development of the newborn infant. Accumulating evidence supports the view that milk's miRNAs significantly contribute to these processes. The most abundant miRNA of milk found in milk fat and milk exosomes is miRNA-148a, which targets DNA methyltransferase 1 (DNMT1), a pivotal epigenetic regulator that suppresses transcription. Furthermore, milk-derived miRNA125b, miRNA-30d, and miRNA-25 target TP53, the guardian of the genome that interacts with DNMT1 and regulates metabolism, cell kinetics, and apoptosis. Thus, the question arose whether cow's milk-derived miRNAs may modify epigenetic regulation of the human milk consumer.
\end{abstract}

Methods: To understand the potential impact of dairy milk consumption on human epigenetics, we have analyzed all relevant research-based bioinformatics data related to milk, milk miRNAs, epigenetic regulation, and lactation performance with special attention to bovine miRNAs that modify gene expression of DNA methyltransferase 1 (DNMT1) and p53 (TP53), the two guardians of the mammalian genome. By means of translational research and comparative functional genomics, we investigated the potential impact of cow's milk miRNAs on epigenetic regulation of human DNMT1, TP53, FOXP3, and FTO, which are critically involved in immunologic and metabolic programming respectively. miRNA sequences have been obtained from mirbase.org. miRNA-target site prediction has been performed using TargetScan release 7.0. 
Results: The most abundant miRNA of cow's milk is miRNA-148a, which represents more than $10 \%$ of all miRNAs of cow's milk, survives pasteurization and refrigerated storage. The seed sequence of human and bovine miRNA-148a-3p is identical. Furthermore, human and bovine DNMT1 mRNA share $88 \%$ identity. The miRNA-148a 7mer seed is conserved in human and bovine DNMT1 mRNA respectively, which may allow for the strong binding of bovine miRNA148a to human DNMT1 mRNA. Consequently, we hypothesize that bovine milk miRNA-148a protected by highly resistant milk exosome membranes - may reach the systemic circulation of the milk consumer targeting and suppressing human DNMT1 mRNA. Attenuated DNMT1 expression associated with reduced $\mathrm{CpG}$ promoter methylation upregulates gene expression of developmental genes such as FOXP3 and FTO. Milk-derived miRNA-125b, miRNA-30d, and miRNA-25 via targeting TP53 may downregulate p53, which physically interacts with and stabilizes DNMT1. Enhancement of dairy lactation performance is associated with increased expression of bovine milk miRNA-148a, a modification that may further increase the miRNA-148a load of dairy milk.

Conclusion: Translational evidence and comparative functional genomics support our hypothesis that bovine milk miRNA signaling may suppress human DNMT1-mediated epigenetic regulation and p53 signaling, which closely interacts with the epigenetic and transcriptional regulation of growth, metabolism, cell cycle progression, and apoptosis. Human and bovine milk miRNAs are able to target DNMT1 and TP53 mRNAs, share identical seed sequences, and resist pasteurization. Pasteurization and refrigeration of dairy milk conserves the gene regulatory software of milk and allows its unrestricted entry into the human food chain. The continued exposure of modern humans to milk's epigenetic machinery since the widespread distribution of refrigerators is a novel change of human nutrition which may promote diseases of Western civilization.

Keywords: adipogenesis, dairy, DNA methyltransferase 1, epigenetics, exosome, miRNA-148a, miRNA-125b, milk, obesity, p53, Parkinson disease, prostate cancer

\section{BACKGROUND}

Milk has been identified as a postnatal signaling system that promotes postnatal metabolic and immunological programming [1-8]. According to the functional hypothesis $[9,10]$, milk-derived miRNAs may play a key role in milk signaling. Milk is the human body fluid that contains the highest amounts of RNAs and miRNAs [10]. These miRNAs are predominantly secreted by mammary epithelial cells (MECs) and are transported via extracellular vesicles (exosomes) to fulfill their regulatory tasks in the complex setting of mammalian reproduction [5-8,12]. There is increasing evidence that this specific encapsulation of milk miRNAs in exosomes $(30-100 \mathrm{~nm}$ in diameter) and exosome-like vesicles (> $100 \mathrm{~nm}$ ) confers protection against miRNA degradation and creates a long-distance signaling pathway for intestinal and vascular endothelial transport by endocytosis, in addition to miRNA delivery to peripheral tissues [13-20]. It has recently been demonstrated that human milk exosomes and their miRNAs survive digestion in vitro and are taken up by human intestinal cells [21]. Moreover, trans-epithelial transport of bovine milk exosomal miRNAs across intestinal Caco-2 cell monolayers indicated their potential to cross the human intestinal barrier $[13,22]$. Recent labeling studies support the view that bovine milk exosomes 
including their RNAs reach the systemic circulation and are bioavailable after oral administration to mice [23-26].

Cow's milk exosomes protect miRNAs against harsh digestive processes and enable their crossing of the intestinal barrier to reach the blood circulation for distant cellular effects [22]. Notably, there is no significant difference in the levels of miRNA-148a, miRNA-21, and miRNA-25 between in vitro digested exosomes and their respective undigested controls [22]. Importantly, miRNA-148a has been identified as the most prevalent miRNA of human and bovine skim milk and milk fat comprising more that $10 \%$ of all milk-derived miRNAs [27-29]. It has recently been confirmed that the great majority of human and bovine milk miRNAs including miRNA-148a and miRNA200c survive pasteurization [27, 29]. Consumption of commercial milk resulted in a dosedependent increase of miRNA-200c and miRNA-29b in peripheral blood mononuclear cells of healthy adult human volunteers and corresponding changes in gene expression [30]. Thus, accumulating evidence points to the functional capability of human and bovine milk miRNAs to survive gastrointestinal degradation, pasteurization, homogenization, and refrigerated storage [15, $21,27,29,31,32]$. It has recently been demonstrated that the expression of miRNA-148a of normal human colon cells (CRL1831) and K562 human chronic myeloid leukemia cells increased after incubation with either milk exosomes or the fat layer isolated from human milk [29]. In fact, the increased cellular expression of miRNA-148a was associated with a significant decrease in the expression of DNMT1 [14]. Taken together, accumulating indirect evidence supports our hypothesis that bovine milk miRNA-148a enters the human food chain and may modify human DNMT1 expression and systemic gene regulation of the milk recipient [7].

\section{METHODS}

By means of translational research and comparative functional genomics, we investigated the potential impact of bovine milk miRNAs on epigenetic regulation of human DNMT1 and TP53, which are critically involved in gene regulation and transcription. miRNA sequences have been obtained from mirbase.org. Target site prediction has been performed using Target Scan (Release 7.0) [33].

\section{RESULTS}

\section{Human DNMT1: A potential target of bovine milk miRNA-148a}

DNA methylation is one of the best characterized epigenetic modifications. It is generally accepted that DNA methylation promotes gene silencing, while DNA demethylation enhances transcription [34]. DNA methylation serves as a cellular memory system and is dynamically regulated through the action of DNA methyltransferases (DNMTs) [34]. Remarkably, DNA methylation and histone methylation are coupled processes. Notably, DNA methyltransferase 1 (DNMT1), its accessory protein UHRF1 and their associated proteins help maintain DNA methylation and histone methylation through mitotic cell division in a coordinated way [35]. The function of DNMT1 is tightly related to growth control [36]. DNA methylation represses genes partly by the recruitment of the methyl-CpG-binding protein $\mathrm{MeCP} 2$, which in turn leads to recruitment of histone deacetylases [37]. DNMT1 is associated with histone deacetylase activity in vivo [37]. One of the known histone deacetylases, HDAC1, directly binds to DNMT1 [37]. Thereby, DNMT1-mediated 
DNA methylation alters the chromatin state via HDAC activity [37]. The DNMT1 complex with $\mathrm{HDAC1}, \mathrm{Rb}$, and E2F1 represses transcription from E2F-responsive promoters [37], suggesting their involvement in transcriptional repression of chromatin by means of histone deacetylation [38]. DNMT1 activity via maintenance of the appropriate histone $\mathrm{H} 3$ modifications contributes to the preservation of the correct organization of large heterochromatic regions [39]. Furthermore, DNMT1 has been shown to physically interact and bind to the guardian of the genome p53 and co-localizes with p53 in the nucleus [38]. Upon p53 induction, a reporter construct containing the promoter of the anti-apoptotic gene survivin (BIRC5), which contains a natural p53 binding site, was methylated in wild type HCT116 cells but not in DNMT1 null or p53 null cells. Endogenous survivin gene repression involves cooperation between DNMT1 and p53, which is relieved by introduction of DNMT1- or p53-specific small inhibitory RNA (siRNA) [38]. p53 stabilizes the p53-DNMT1-HDAC1 complex [38]. DNMT1 potentially provides a key interaction via DNA methylation recruiting HDAC1 and acting as a bridge between nuclear p53 and chromatin, reinforcing a repressed chromatin state [40].

It is conceivable that milk, which is donated during the postnatal growth period of newborn mammals, enhances gene transcription and growth by suppressing DNMT1 gene expression. Do et al. [41] recently confirmed that miRNA-148a belongs to the most abundantly expressed miRNAs of bovine milk since it accounts for more than $10 \%$ of the read counts in each stage of dairy cow lactation. miRNA-148a has also been identified as the most abundant miRNA in human milk [21, 28, 29]. miRNA-148a, miRNA-148b, and miRNA-152 are three members of the miRNA-148/152 family which share substantial homology in their seed sequences [42]. Notably, the seed sequence of human (hsa) and bovine (bta) miRNA-148a-3p are identical (Table 1). It is of functional importance that miRNA-148a directly targets DNMT1 [43]. It has been demonstrated that the expression of miRNA-148a of normal human colon cells (CRL1831) and K562 human leukemia cells increased after incubation with milk exosomes and the fat layer isolated from human milk, respectively [29]. This was associated with a significant decrease in the expression of DNMT1 in both cell types [29]. This experiment is a proof-of-concept demonstrating that the addition of milk exosomes, a source of MEC-derived miRNA-148a, increases intracellular miRNA-148a levels of recipient cells resulting in corresponding downregulation of DNMT1 expression. For instance, gene expression of the key transcription factor of regulatory T-cells, FOXP3, critically depends on epigenetic regulation and is upregulated by FOXP3 promoter demethylation [44]. Admyre et al. [45] showed that the addition of human milk exosomes to peripheral blood mononuclear cells significantly enhanced the expression of FoxP3. In infants with cow's milk allergy, a linear correlation between the extent of FOXP3 promoter demethylation and FoxP3 expression could be detected [46]. These observations are in line with our view that milk exosome-derived miRNA-148a via targeting DNMT1 enhances FoxP3 expression [4,27]. There are further genes such as INS, IGF1, and FTO which promote anabolism and growth, that are also epigenetically upregulated via promoter demethylation recently reviewed elsewhere [7]. Apparently, epigenetic upregulation of developmental and lactation-related genes by miRNA148a-mediated suppression of DNMT1 appears to represent a key epigenetic signature of lactation and milk signaling.

miRNA-21 is another abundant miRNA of human and cow's milk [29, 47], which indirectly inhibits DNMT1 expression by targeting Ras guanyl nucleotide-releasing protein-1 (RASGRP1) 
[46]. The expression of DNMT1 has been inversely related to the expression miRNA-148a and its homolog miRNA-152 [29,48,49].

Table 1. Sequence of DNMT1-targeting human and bovine miRNA-148a (seed in bold; mirbase.org)

\section{hsa-miRNA-148a-3p \\ 5' UCAGUGCACUACAGAACUUUGU}

bta-miRNA-148a-3p

5' UCAGUGCACUACAGAACUUUGU

The recent study of Golan-Gerstl et al. [29] demonstrates that miRNA-148a-3p sequences are highly conserved among various species including humans (Homo sapiens) and cows (Bos taurus). This means that bovine milk miRNA-148a may be able to target human DNMT1 mRNA.

As shown in Table 2 human DNMT1 mRNA contains a potent 7 mer target site for human and bovine miRNA-148a.

Table 2. Predicted base pairing of human and bovine miRNA-148a with position 48-55 of human DNMT1 3'UTR (seed in bold; TargetScan)

hsa-miRNA-148a-3p

DNMT1 3'UTR (position 48-55)

bta-miRNA-148a-3p

$\begin{array}{cc}3^{\prime} & \text { UGUUUCAAGACAUCACGUGACU } \\ \text { I I I I I I I } \\ 5^{\prime} \ldots \text { CAGGAAUCCCCAACAUGCACUGA... } \\ \text { I I I I I I I } \\ 3^{\prime} \quad \text { UGUUUCAAGACAUCACGUGACU }\end{array}$

I I I I I I I

I I I I I I I

3' UGUUUCAAGACAUCACGUGACU

Bovine DNMT1 mRNAs displays a strong sequence homology to human DNMT1 mRNA $[50,51]$. Remarkably, all of the DNMTs with an important role in DNA methylation including DNMT1 show a greater degree of structural similarity between human and bovine than between human and mouse [51]. Human DNMT1 contains 1616 amino acids and bovine DNMT1 1611 amino acids, respectively. Amino acid sequence identity of $88 \%$ has been reported [51].

\section{Bovine miRNA-148a promotes lactation performance}

Genetic and epigenetic selection of dairy cows intended to increase lactation performance and milk yield further enhanced the expression of lactation-promoting miRNAs, especially of miRNA-148a $[41,52]$. Co-expression network and pathway analyses correlated abundantly expressed bovine miRNA-148a with milk yield [53]. Accordingly, Wang et al. [54] reported that the expression of the miRNA-148a family member miRNA-152 significantly increased during lactation in MECs of dairy cows producing high quality milk compared to the lower miRNA-152 levels in cows producing low quality milk. The forced expression of miRNA-152 in dairy cow MECs resulted in a marked reduction of DNMT1 at both the mRNA and protein levels [54]. Additionally, miRNA148a has been shown to induce milk triacylglycerol synthesis in goat MECs [55]. Intriguingly, the expression of miRNA-148a was significantly enhanced by hormone (dexamethasone, insulin, and 
prolactin) treatment. Significantly, increased extracellular levels of miRNA-148a have been detected in MEC culture medium pointing to an extracellular transfer of miRNA-148a [56]. Altogether, increased dairy cow lactation performance is associated with the enhanced expression of bovine miRNA-148a/152, which may increase in dairy milk obtained from high performance dairy cows. Thus, experimental evidence supports the fact that bovine miRNAs of the miRNA148a/152 family suppress DNMT1 increasing lactation and milk yield.

\section{Interaction between DNMT1 and p53}

Endogenous survivin gene repression involves cooperation between DNMT1 and p53 and is relieved by introduction of DNMT1- or p53-specific small inhibitory RNA [38]. It is thereby conceivable that milk-derived miRNAs may target TP53 mRNA and further augment the epigenetic activity of miRNA-148a-mediated DNMT1 silencing. In fact, miRNAs are important regulators of p53 expression and its signaling pathway [57]. As discussed for the survivin promoter, p53 stabilizes the p53-DNMT1-HDAC1 complex (Fig. 1) [38]. The expression of the p53 gene (TP53) is tightly regulated via transcriptional and post-translational modulations. Le et al. [58] demonstrated that miRNA-125b is a bona fide negative regulator of $\mathrm{p} 53$ in both zebrafish and humans. miRNA-125b-mediated down-regulation of p53 is strictly dependent on the binding of miRNA-125b to a miRNA response element in the 3'-UTR of TP53 mRNA. Notably, miRNA$125 \mathrm{~b}$ regulation of p53 is conserved at the network level in all vertebrates [59]. Milk contains abundant miRNA-125b, which has been demonstrated in human [60], bovine [15,32], and porcine milk exosomes [61] respectively. Further known p53- targeting miRNAs are miRNA-30d, miRNA-25, and miRNA-504 [62]. miRNA-25 and miRNA-30d directly target the 3'-UTR of TP53 downregulating p53 protein levels, thereby reducing the expression of p53-regulated genes [62]. miRNA-30d has been detected as a signature miRNA of mature raw and commercial milk of dairy cows [47]. miRNA-30d has also been found in porcine milk exosomes and in human milk [32, 63, 64]. Additionally, miRNA-25-3p has been observed in human and porcine milk exosomes [60, 63]. Remarkably, the mature seed sequences of human and bovine miRNA-125b, miRNA-25, in addition to miRNA-30d, are identical (Table 3).

Table 3. Sequences of p53-targeting human and bovine microRNAs (seed in bold; mirbase.org)

\begin{tabular}{|l|l|}
\hline $\begin{array}{l}\text { hsa-miRNA-125b } \\
\text { 5' UCCCUGACACCCUAACUUGUGA }\end{array}$ & $\begin{array}{l}\text { bta-miRNA-125b } \\
5^{\prime} \text { UCCCUGACACCCUAACUUGUG }\end{array}$ \\
\hline $\begin{array}{l}\text { hsa-miRNA-30d } \\
5^{\prime} \text { UGUAAACAUCCCCGACUGGAAG }\end{array}$ & $\begin{array}{l}\text { bta-miRNA-30d } \\
5^{\prime} \text { UGUAAACAUCCCCGACUGGAAGCU }\end{array}$ \\
\hline $\begin{array}{l}\text { hsa-miRNA-25-3p } \\
5^{\prime} \text { AGUCUGGCUCUGUUCACGUUAC }\end{array}$ & $\begin{array}{l}\text { b'A-miRNA-25-3p } \\
5^{\prime} \text { AGUCUGGCUCUGUUCACGUUAC }\end{array}$ \\
\hline
\end{tabular}


miRNA-125b exhibits the strongest binding affinities of the three TP53-targeting miRNAs detected in milk. It is significant to mention that these milk-derived miRNAs target different sites of the TP53 3'UTR (Table 4).

Table 4. Predicted base pairing of miRNA-125, miRNA-30d, and miRNA-25 with human TP53 3'UTR mRNA (seed in bold; TargetScan).

\begin{tabular}{|c|c|}
\hline hsa-miRNA-125-5p & $\begin{array}{r}3^{\prime} \text { AGUGUUCAAUCCCAGAGUCCCU } \\
\text { I I I I I I I }\end{array}$ \\
\hline TP53 3`UTR (position 1022-1026 & $\begin{array}{r}5^{\prime} \ldots \text { AAGACUUGUUUUAUGCUCAGGGU... } \\
\text { I I I I I I }\end{array}$ \\
\hline bta-miRNA-125p & GUGUUCAAUCCCACAGUCCCU \\
\hline hsa-miRNA-30d-5p & $\begin{array}{l}\text { 3’ GAAGGUCAGCCCCUA- - CAAAUGU } \\
\text { I I I I I I }\end{array}$ \\
\hline TP53 3’UTR (position 576-582) & $\begin{array}{c}5^{\prime} \text { UGCAGUUAAGGGUUAGUUUACAA... } \\
\text { I I I I I I }\end{array}$ \\
\hline bta-miRNA-30d-5p & 3' UCGAAGGUCAGCCCCUACAAAUGU \\
\hline hsa-miRNA-25-3p & $\begin{array}{r}3^{\prime} \text { AGUCUGGCUCUGUUCACGUUAC } \\
\text { I I I I I I }\end{array}$ \\
\hline TP53 3'UTR (position 381-387) & $\begin{array}{c}5^{\prime} \ldots \text { CUUUGAACCCUUGCUUGCAAUAG... } \\
\text { I I I I I I }\end{array}$ \\
\hline bta-miRNA-25-3p & 3' AGUCUGGCUCUGUUCACGUUAC \\
\hline
\end{tabular}

Altogether, these data imply that milk-derived miRNAs, especially milk miRNA-125b, may impair the expression of p53 and consequently p53-mediated gene regulation in milk consuming humans. Importantly, p53, the guardian of the genome [65], controls a vast regulatory transcriptional network including most critical checkpoints of cell cycle progression, apoptosis, and metabolism [66, 67], in addition to interacting with and stabilizing DNMT1 [38].

\section{DISCUSSION}

The abundance of miRNA-148a in milk and its high interspecies homology implies that milk miRNA-mediated regulation is a highly conserved archaic signaling pathway of mammals. Recent data support the view that dairy milk miRNAs including miRNA-148a survive pasteurization, processing, and refrigerated storage and thereby enter the human food chain. Efforts of the dairy industry to increase milk yield are associated with exaggerated expression of milk miRNA148a/miRNA-152 and suppression of bovine MEC DNMT1 [41, 53-55]. Significantly, attenuated bovine p53 expression of domestic cows with extended lactation persistence compared to the wild type Bovidae, which has recently been explained by a loss of Bov-A2, a short interspersed nuclear element in the promoter region of TP53 [68]. The identical seed sequence of human and bovine miRNA-148a and its transport via milk exosomes and milk fat globules allows the prediction that dairy milk miRNA-148a reaches the systemic circulation of the milk consumer where it may attenuate human DNMT1 mRNA expression. DNMT1 is a key regulator of DNA methylation, 
histone methylation, histone deacetylation, and p53 interaction. Thus, it is conceivable that bovine milk-derived miRNA-148a via targeting human DNMT1 modifies human gene expression. Physiologically, milk-induced epigenetic regulation may serve to enhance gene expression only during the period of postnatal development and infant growth. Significantly, promoter $\mathrm{CpG}$ demethylation of FTO and FOXP3 and other important developmental genes such as INS, IGF1, $N R F 2, C A V 1, S R E B P 1, G L U T 1, N R 4 A 3$, and $L C T$ have been associated with increased gene expression involved in metabolic programming and immune homeostasis $[69,70]$ (Figure 1).

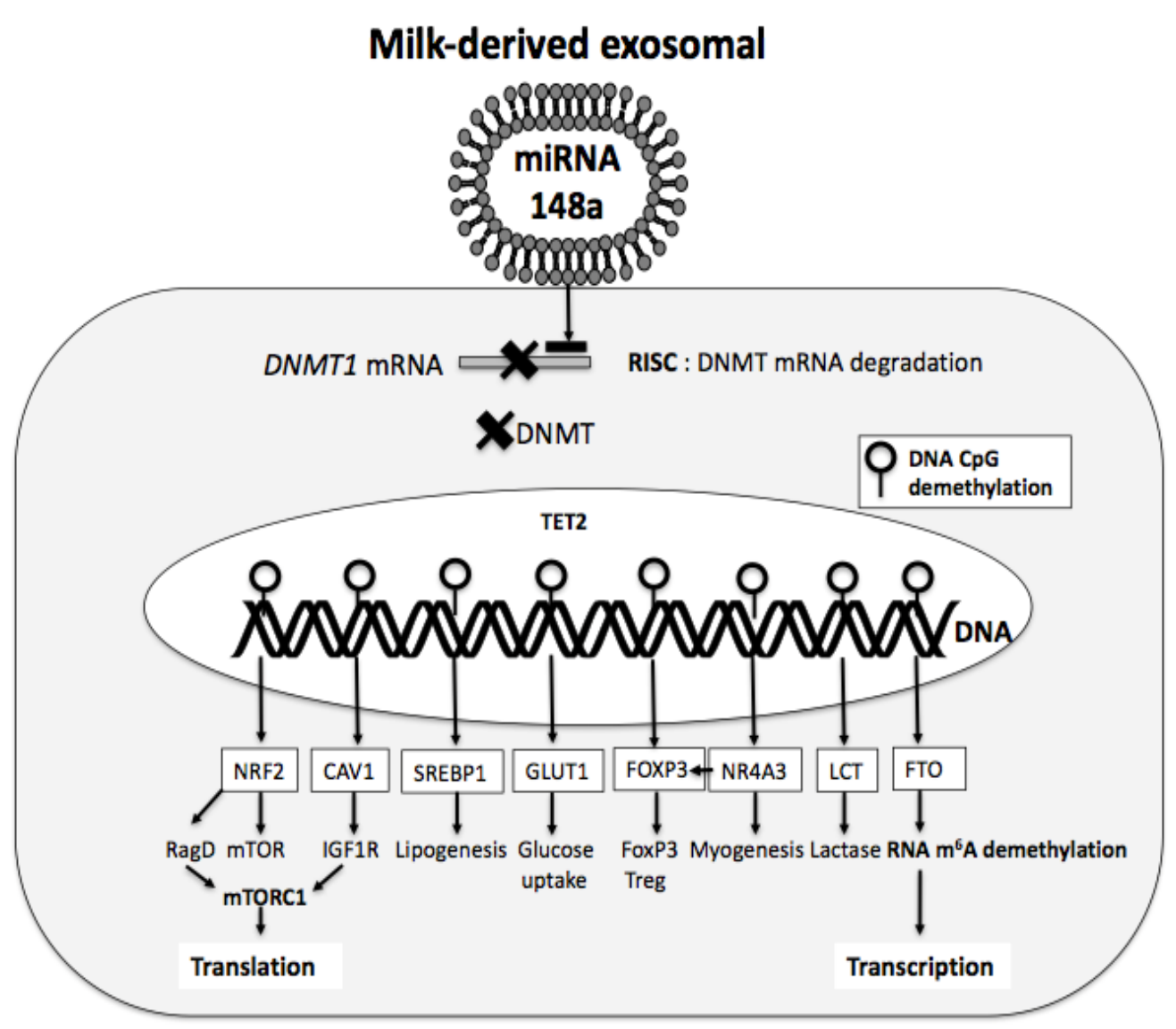

Figure 1. Working model of milk-miRNA-148a-mediated DNMT1 silencing associated with increased gene expression of important developmental genes. Modified according to [7].

Obesity. Recently, miRNA-148a has been associated with obesity in humans and adipocyte differentiation of mesenchymal stem cells through Wnt signaling [71]. miRNA-148a is highly abundant in adipose tissue [72, 73]. miRNA-148a-mediated silencing of DNMT1 accelerates adipocyte differentiation of 3T3-L1 cells [74]. Additionally, miRNA-148a has been identified as a downstream effector of X-box-binding protein 1 that silences Wnt10b during adipogenesis of 3T3-L1 cells [75]. Furthermore, Wnt10b, a strong negative regulator of adipogenesis, has been identified as a direct target miRNA-148a [76]. Persistent intake of bovine miRNA-148a by continued consumption of pasteurized whole and skim milk may thereby be an unrecognized pathogenic factor promoting adipogenesis and obesity in civilized milk-consuming societies. 
Furthermore, milk-derived miRNAs such as miRNA-125b via targeting TP53 may disrupt p53DNMT1-HDAC1 interaction promoting gene expression and unfolding of chromatin structure. The suppression of DNMT1 and p53 apparently represents milk's epigenetic mode of action promoting transcription, postnatal growth, and adipogenesis (Figure 2).

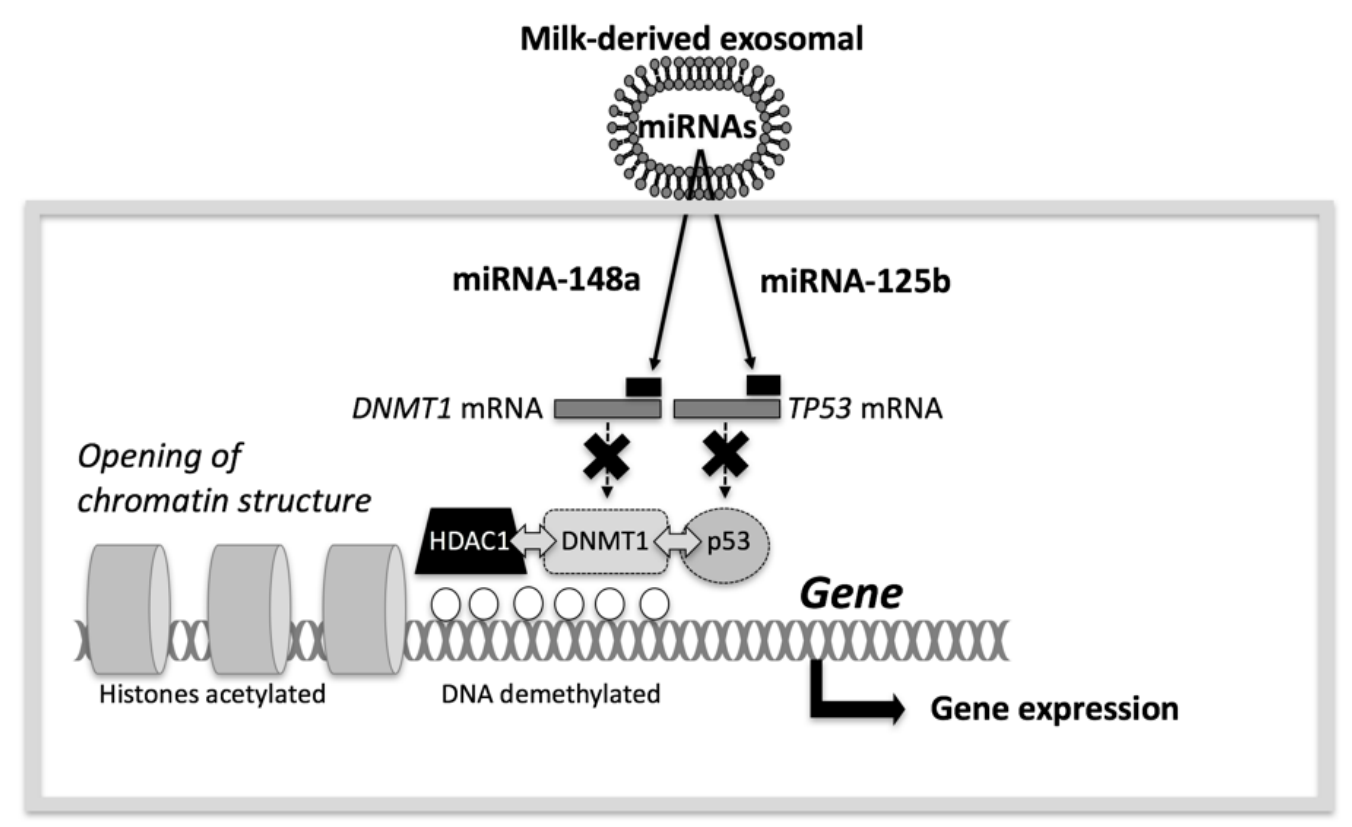

Figure 2. Working model illustrating the potential impact of milk-derived miRNAs targeting DNMT1 and p53 expression, the key epigenetic and transcriptional regulators of the milk recipient promoting gene expression and transcription.

Interestingly, p53 knockout enhanced adipogenesis and the expression of adipogenic marker genes, whereas its overexpression markedly reduced adipogenesis and marker gene expression in 3T3-L1 preadipocytes [77]. Newly weaned mice who had access to whole cow's milk for 17 weeks consumed more calories and increased body and fat mass [78]. Remarkably, a recent meta-analysis identified MIR148A as a new locus associated with increased body mass in individuals of African ancestry [79], which is associated with obesity and type 2 diabetes mellitus [80]. The EPIC-Interact study $(n=340,234)$ [81] demonstrated an increased association of type 2 diabetes mellitus with the consumption of unfermented cow's milk in contrast to fermented milk products such as yoghurt, which are depleted in exosomal miRNAs [19].

Prostate cancer. Lee et al. [82] demonstrated that reduced expression of DNMT1 plays an important role in the induction of epithelial-mesenchymal transition (EMT) and cancer stem cells (CSC) phenotype by prostate cancer (PCa) cells, with enhanced tumorigenesis and metastasis. The authors confirmed that silencing DNMT1 is correlated with enhancement of the induction of EMT and the CSC phenotype in PCa cells [82]. Thus, milk-miRNA-148a-mediated suppression of DNMT1 may promote EMT and CSC phenotype of PCa cells. A population-based Swedish study provided evidence that lactose intolerance, which is associated with a reduced intake of milkderived miRNAs, reduces the risk of lung, breast, and ovarian cancers [83]. The incidence of lactose intolerance in PCa patients has been reported to be less than that in the general population 
[84]. A significantly greater number of PCa patients in the lactose-tolerant group had a milk intake $>500 \mathrm{ml} /$ day than those in the intolerant group [84].

Parkinson's disease. DNMT1 is abundantly expressed in the adult brain [50] and is mainly located in the nuclear compartment, where it has access to chromatin. Hypomethylation of $\mathrm{CpG}$ islands at intron 1 of the SNCA gene has been reported to result in overexpression of $\alpha$-synuclein in Parkinson's disease (PD) [85]. In fact, reduced nuclear DNMT1 levels have been detected in human postmortem brain samples from PD patients and dementia with Lewy bodies (DLB) [85]. Quantitative analysis by clonal assay showed that the CpG 2 of SNCA was hypomethylated in PD patients compared with the normal control [86]. Furthermore, the methylation rate at $\mathrm{CpG} 4$ in intron 1 of SNCA and the overall mean methylation rate at these sites were significantly lower in DLB patients than in healthy controls [87]. Milk-miRNA-148a-mediated suppression of DNMT1 may thereby explain the overexpression of $\alpha$-synuclein, a key player involved in the pathogenesis of PD and DLB. Epidemiological evidence showed significant positive associations for PD risk in men with lactose intake [88], which again may be indicative of persistent milk miRNA uptake.

\section{CONCLUSION}

In all mammals except humans, milk's epigenetic signaling is restricted to the postnatal period. Only modern humans may be exposed during their entire life period to milk-derived miRNA signaling and milk-dependent epigenetic regulation. In this regard, pasteurized dairy milk represents a most critical functional food that transfers archaic, highly conserved miRNAs into the human food chain. It should be kept in mind that already minor amounts of miRNAs exert significant biological effects [89], especially if they are provided consistently. Before the era of the refrigerator, humans mostly consumed fermented milk and fermented milk products. Recent evidence underlines that fermentation deteriorates milk-derived exosomal miRNAs [19], while pasteurization and refrigerated storage of milk exposes the human milk consumer to bioactive miRNAs of milk [21, 22,27-32].

In terms of evolutionary biology, persistent consumption of the milk of another species is a relatively novel behavioral pattern in human nutrition [90]. In the 1950s, this pattern was modified by the introduction of pasteurization and refrigeration allowing milk's miRNAs to enter the human food chain [7]. Milk is apparently the most active functional food with greatest impact on human development, growth, health and disease. Continued milk-miRNA-mediated downregulation of DNMT1 and p53 may not only explain the increase in linear growth and body mass of milk consuming children [91-95], but also the long-term increased risk of PCa and PD [96-101]. A multitude of biological parameters explains why shorter or smaller people have lower risks of cardiovascular disease and greater longevity [102]. In contrast, higher milk intake increases linear growth and mortality [92, 98].

Many factors such as the precise kinetics and uptake of dairy milk miRNAs by human milk consumers are still uncertain, which thereby warrants further investigations. Future miRNA research should thus focus on milk miRNA-148a and miRNA-125b uptake and its predicted impact on DNMT1 and p53 gene expression in human milk consumers and its long-term consequences on human health. We recommend to eliminate dairy milk miRNAs from the human food chain. 
List of Abbreviations: CSC, cancer stem cell; DLB, dementia with Lewy bodies; DNMT1, DNA methyltransferase 1; FOXP3, forkhead box P3; FTO, fat mass- and obesity- associated gene; HDAC1, histone deacetylase 1; miRNA, micro-ribonucleic acid, MEC, mammary epithelial cell, mTORC1, mechanistic target of rapamycin complex 1; PCa, prostate cancer; PD, Parkinson disease; SNCA, synuclein alpha, TP53, tumor protein p53; UHRF1, ubiquitin-like protein containing PHD and ring finger domains 1; UTR, untranslated region;

Authors Contributions: B.C.M. designed the research, formulated the hypothesis and wrote major parts of the manuscript. G.S. checked the miRNA data bases and controlled computed miRNA base pairing research. Both authors approved the final manuscript.

Competing Interests: There are no conflicts of interest to declare.

Acknowledgments and Funding: The authors thank Dr. Bruno Steinkraus, Oxford University, for his support in computerized miRNA base pairing predictions. There was no funding for this study.

\section{REFERENCES}

1. Melnik BC, John SM, Schmitz G: Milk is not just food but most likely a genetic transfection system activating mTORC1 signaling for postnatal growth. Nutr J 2013, 12:103.

2. Melnik BC: Milk - a nutrient system of mammalian evolution promoting mTORC1 dependent translation. Int J Mol Sci 2015, 16:17048-17087.

3. Alsaweed M, Hartmann PE, Geddes DT, Kakulas F: MicroRNAs in breastmilk and the lactating breast: Potential immunoprotectors and developmental regulators for the infant and the mother. Int J Environ Res Public Health 2015, 12:13981-14020.

4. Melnik BC, John SM, Carrera-Bastos P, Schmitz G: Milk: a postnatal imprinting system stabilizing FoxP3 expression and regulatory $\mathrm{T}$ cell differentiation. Clin Transl Allergy 2016, 6:18.

5. Floris I, Kraft JD, Altosaar I: Roles of microRNA across prenatal and postnatal periods. Int J Mol Sci 2016, 17:pii:E1994.

1. Zempleni J, Aguilar-Lozano A, Sadri M, Sukreet S, Manca S, Wu D, Zhou F, Mutai E: Biological activities of extracellular vesicles and their cargos from bovine and human milk in humans and implications for infants. J Nutr 2017, 147:3-10.

2. Melnik BC, Schmitz G: Milk's role as an epigenetic regulator in health and disease. Diseases 2017, 5:12.

3. Perge P, Nagy Z, Decmann Á, Igaz I, Igaz P: Potential relevance of microRNAs in interspecies epigenetic communication, and implications for disease pathogenesis. RNA Biol 2017, 14:391-401.

4. Melnik BC, Kakulas F, Geddes DT, Hartmann PE, John SM, Carrera-Bastos P, Cordain L, Schmitz G: Milk miRNAs: simple nutrients or systemic functional regulators? Nutr Metab (Lond) 2016, 13:42.

6. Zempleni J: Milk exosomes: beyond dietary microRNAs. Genes Nutr 2017, 12:12. 
7. Weber JA, Baxter DH, Zhang S, Huang DY, Huang KH, Lee MJ, Galsa DJ, Wang K: The microRNA spectrum in 12 body fluids. Clin Chem 2010, 56:1733-1741.

8. Foster BP, Balassa T, Benen TD, Dominovic M, Elmadjian GK, Florova V, Fransolet MD, Kestlerova A, Kmiecik G, Kostadinova IA, Kyvelidou C, Meggyes M, Mincheva MN, Moro L, Pastuschek J, Spoldi V, Wandernoth P, Weber M, Toth B, Markert UR: Extracellular vesicles in blood, milk and body fluids of the female and male urogenital tract and with special regard to reproduction. Crit Rev Clin Lab Sci 2016, 53:379-395.

9. Wolf T, Baier SR, Zempleni J: The intestinal transport of bovine milk exosomes is mediated by endocytosis in human colon carcinoma Caco-2 cells and rat small intestinal IEC-6 cells. J Nutr 2015, 145:2201-2206.

10. Zempleni J, Baier SR, Howard KM, Cui J. Gene regulation by dietary microRNAs. Can J Physiol Pharmacol 2015, 93:1097-1102.

11. Benmoussa A, Lee CH, Laffont B, Savard P, Laugier J, Boilard E, Gilbert C, Fliss I, Provost P: Commercial dairy cow milk microRNAs resist digestion under simulated gastrointestinal tract conditions. J Nutr 2016, 146:2206-2215.

12. Chen T, Xie MY, Sun JJ, Ye RS, Cheng X, Sun RP, Wei LM, Li M, Lin DL, Jiang QY, Xi QY, Zhang YL: Porcine milk-derived exosomes promote proliferation of intestinal epithelial cells. Sci Rep 2016, 6:33862.

13. Kusuma RJ, Manca S, Friemel T, Sukreet S, Nguyen C, Zempleni J: Human vascular endothelial cells transport foreign exosomes from cow's milk by endocytosis. Am J Physiol Cell Physiol 2016, 310:C800-807.

14. Hock A, Miyake H, Li B, Lee C, Ermini L, Koike Y, Chen Y, Määttänen P, Zani A, Pierro A: Breast milk-derived exosomes promote intestinal epithelial cell growth. J Pediatr Surg 2017, 52:755-759.

15. Yu S, Zhao Z, Sun L, Li P: Fermentation results in quantitative changes in milk-derived exosomes and different effects on cell growth and survival. J Agric Food Chem, 2017; 65:1220-1228.

16. Cui J, Zhou B, Ross SA, Zempleni J: Nutrition, microRNAs, and human health. Adv Nutr 2017, 8:105-112.

17. Liao Y, Du X, Li J, Lönnerdal B: Human milk exosomes and their microRNAs survive digestion in vitro and are taken up by human intestinal cells. Mol Nutr Food Res 2017 Jul 7. doi: 10.1002/mnfr.201700082 [Epub ahead of print].

18. Rani P, Vashisht M, Golla N, Shandilya S, Onteru SK, Singh D: Milk miRNAs encapsulated in exosomes are stable to human digestion and permeable to intestinal barrier in vitro. J Funct Foods 2017, 34:431-439.

19. Manca S, Giraud D, Zempleni J: Bioavailability and biodistribution of fluorophore-labeled exosomes from cow's milk after intravenous and oral administration in C57BI/6J mice. FASEB J 2016, 30:690.8.

20. Manca S, Giraud D, Zempleni J: The bioavailability and distribution of bovine milk exosomes is distinct from that of their cargos in mice. FASEB J 2017, 31:148.2.

21. Munagala R, Aqil F, Jeyabalan J, Gupta RC: Bovine milk-derived exosomes for drug delivery. Cancer Lett 2016, 371:48-61. 
22. Agrawal AK, Aqil F, Jeyabalan J, Spencer WA, Beck J, Gachuki BW, Alhakeem SS, Oben K, Munagala R, Bondada S, Gupta RC: Milk-derived exosomes for oral delivery of paclitaxel. Nanomedicine 2017, 13:1627-1636.

23. Kirchner B, Pfaffl MW, Dumpler J, von Mutius E, Ege MJ: microRNA in native and processed cow's milk and its implication for the farm milk effect on asthma. J Allergy Clin Immunol 2016, 137:1893-1895.

24. Munch EM, Harris RA, Mohammad M, Benham AL, Pejerrey SM, Showalter L, Hu M, Shope CD, Maningat PD, Gunaratne PH, Haymond M, Aagaard K: Transcriptome profiling of microRNA by Next-Gen deep sequencing reveals known and novel miRNA species in the lipid fraction of human breast milk. PLoS One 2013, 8:e50564.

25. Golan-Gerstl R, Elbaum Shiff Y, Lavi-Moshayoff V, Schecter D, Leshkowitz D, Reif S: Characterization and biological function of milk-derived miRNAs. Mol Nutr Food Res 2017, Jun 23. doi: 10.1002/mnfr.201700009. [Epub ahead of print].

26. Baier SR, Nguyen C, Xie F, Wood JR, Zempleni J: MicroRNAs are absorbed in biologically meaningful amounts from nutritionally relevant doses of cow milk and affect gene expression in peripheral blood mononuclear cells, HEK-293 kidney cell cultures, and mouse livers. J Nutr 2014, 144:1495-1500.

27. Howard KM, Jati Kusuma R, Baier SR, Friemel T, Markham L, Vanamala J, Zempleni J: Loss of miRNAs during processing and storage of cow's (Bos taurus) milk. J Agric Food Chem 2015, 63:588-592.

28. Baddela VS, Nayan V, Rani P, Onteru SK, Singh D: Physicochemical biomolecular insights into Buffalo milk-derived nanovesicles. Appl Biochem Biotechnol 2016, 178: 544-557.

29. Agarwal V, Bell GW, Nam JW, Bartel DP: Predicting effective microRNA target sites in mammalian mRNAs. Elife 2015, 4. doi: 10.7554/eLife.05005.

30. Li E, Zhang Y: DNA methylation in mammals. Cold Spring Harb Perspect Biol 2014, 6:a019133.

31. Hashimoto H, Vertino PM, Cheng X: Molecular coupling of DNA methylation and histone methylation. Epigenomics 2010, 2:657-669.

32. Szyf M: The role of DNA methyltransferase 1 in growth control. Front Biosci 2001, 6:D599-609.

33. Fuks F, Burgers WA, Brehm A, Hughes-Davies L, Kouzarides T: DNA methyltransferase Dnmt1 associates with histone deacetylase activity. Nat Genet 2000, 24:88-91.

34. Estève PO, Chin HG, Pradhan S: Human maintenance DNA (cytosine-5)methyltransferase and p53 modulate expression of p53-repressed promoters. Proc Natl Acad Sci U S A 2005, 102:1000-1005.

35. Espada J, Ballestar E, Fraga MF, Villar-Garea A, Juarranz A, Stockert JC, Robertson KD, Fuks F, Esteller M: Human DNA methyltransferase 1 is required for maintenance of the histone H3 modification pattern. J Biol Chem 2004, 279:37175-37184.

36. Hoffman WH, Biade S, Zilfou JT, Chen J, Murphy M: Transcriptional repression of the anti-apoptotic survivin gene by wild type p53. J Biol Chem 2002, 277:3247-3257. 
37. Do DN, Li R, Dudemaine PL, Ibeagha-Awemu EM: MicroRNA roles in signallin during lactation: an insight from differential expression, time course and pathway analyses of deep sequence data. Sci Rep 2017, 7:44605.

38. Chen Y, Song YX, Wang ZN: The microRNA-148/152 family: multi-faceted players. Mol Cancer 2013, 12:43.

39. Pan W, Zhu S, Yuan M, Cui H, Wang L, Luo X, Li J, Zhou H, Tang Y, Shen N: MicroRNA21 and microRNA-148a contribute to DNA hypomethylation in lupus CD4+ T cells by directly and indirectly targeting DNA methyltransferase 1. J Immunol 2010, 184:67736781.

40. Huehn J, Beyer M: Epigenetic and transcriptional control of Foxp3+ regulatory T cells. Semin Immunol 2015, 27:10-18.

41. Admyre C, Johansson SM, Qazi KR, Filén JJ, Lahesmaa R, Norman M, Neve EP, Scheynius A, Gabrielsson S: Exosomes with immune modulatory features are present in human breast milk. J Immunol 2007, 179:1969-1978.

42. Paparo L, Nocerino R, Cosenza L, Aitoro R, D’Argenio V, Del Monaco V, Di Scala C, Amoroso A, Di Costanzo M, Francesco Salvatore F, Berni Canani R: Epigenetic features of FoxP3 in children with cow's milk allergy. Clinical Epigenetics 2016, 8:86.

43. Chen X, Gao C, Li H, Huang L, Sun Q, Dong Y, Guan D, Hu X, Zhao S, Li L, Zhu L, Yan Q, Zhang J, Zen K, Zhang CY: Identification and characterization of microRNAs in raw milk during different periods of lactation, commercial fluid, and powdered milk products. Cell Res 2010, 20:1128-1137.

44. Long XR, He Y, Huang C, Li J: MicroRNA-148a is silenced by hypermethylation and interacts with DNA methyltransferase 1 in hepatocellular carcinogenesis. Int J Oncol 2014, 44:1915-1922.

45. Xu Q, Jiang Y, Yin Y, Li Q, He J, Jing Y, Qi YT, Xu Q, Li W, Lu B, Peiper SS, Jiang BH, Liu LZ: A regulatory circuit of miR-148a/152 and DNMT1 in modulating cell transformation and tumor angiogenesis through IGF-IR and IRS1. J Mol Cell Biol 2013, 5:3-13.

46. Golding MC, Westhusin ME: Analysis of DNA (cytosine 5) methyltransferase mRNA sequence and expression in bovine preimplantation embryos, fetal and adult tissues. Gene Expr Patterns 2003, 3:551-558.

47. Rodriguez-Osorio N, Wang H, Rupinski J, Bridges SM, Memili E: Comparative functional genomics of mammalian DNA methyltransferases. Reprod Biomed Online 2010, 20:243255.

48. Braud M, Magee DA, Park SD, Sonstegard TS, Waters SM, MacHugh DE, Spillane C: Genome-wide microRNA binding site variation between extinct wild aurochs and modern cattle identifies candidate microRNA-regulated domestication genes. Front Genet 2017, 8:3.

49. Do DN, Dudemaine PL, Li R, Ibeagha-Awemu EM: Co-expression network and pathway analyses reveal important modules of miRNAs regulating milk yield and component traits. Int J Mol Sci 2017, 18:1560. 
50. Wang J, Bian Y, Wang Z, Li D, Wang C, Li Q, Gao X: MicroRNA-152 regulates DNA methyltransferase 1 and is involved in the development and lactation of mammary glands in dairy cows. PLoS One 2014, 9:e101358.

51. Chen Z, Luo J, Sun S, Cao D, Shi H, Loor JJ: miR-148a and miR-17-5p synergistically regulate milk TAG synthesis via PPARGC1A and PPARA in goat mammary epithelial cells. RNA Biol 2017, 14:326-338.

52. Muroya S, Hagi T, Kimura A, Aso H, Matsuzaki M, Nomura M: Lactogenic hormones alter cellular and extracellular microRNA expression in bovine mammary epithelial cell culture. J Anim Sci Biotechnol 2016, 7:8.

53. Liu J, Zhang C, Zhao Y, Feng Z: MicroRNA control of p53. J Cell Biochem 2017, 118:714.

54. Le MT, Teh C, Shyh-Chang N, Xie H, Zhou B, Korzh V, Lodish HF, Lim B: MicroRNA$125 \mathrm{~b}$ is a novel negative regulator of $\mathrm{p} 53$. Genes Dev 2009, 23:862-876.

55. Le MT, Shyh-Chang N, Khaw SL, Chin L, Teh C, Tay J, O'Day E, Korzh V, Yang H, Lal A, Lieberman J, Lodish HF, Lim B: Conserved regulation of p53 network dosage by microRNA-125b occurs through evolving miRNA-target gene pairs. PLoS Genet 2011, 7:e1002242.

56. Zhou Q, Li M, Wang X, Li Q, Wang T, Zhu Q, Zhou X, Wang X, Gao X, Li X: Immunerelated microRNAs are abundant in breast milk exosomes. Int J Biol Sci 2012, 8:118-123.

57. Chen T, Xi QY, Ye RS, Cheng X, Qi QE, Wang SB, Shu G, Wang LN, Zhu XT, Jiang QY, Zhang YL: Exploration of microRNAs in porcine milk exosomes. BMC Genomics 2014, 15:100.

58. Kumar M, Lu Z, Takwi AA, Chen W, Callander NS, Ramos KS, Young KH, Li Y: Negative regulation of the tumor suppressor p53 gene by microRNAs. Oncogene 2011, 30:843-853.

59. Gu Y, Li M, Wang T, Liang Y, Zhong Z, Wang X, Zhou Q, Chen L, Lang Q, He Z, Chen X, Gong J, Gao X, Li X, Lv X: Lactation-related microRNA expression profiles of porcine breast milk exosomes. PLoS One 2012; 7:e43691.

60. Alsaweed M, Lai CT, Hartmann PE, Geddes DT, Kakulas F: Human milk cells contain numerous miRNAs that may change with milk removal and regulate multiple physiological processes. Int J Mol Sci 2016, 17:pii:E956.

61. Lane DP. Cancer. p53, guardian of the genome. Nature 1992, 358:15-16.

62. Fischer M: Census and evaluation of p53 target genes. Oncogene 2017, 36:3943-3956.

63. Flöter J, Kaymak I, Schulze A: Regulation of metabolic activity by p53. Metabolites 2017, 7 pii:E21.

64. Dekel Y, Machluf Y, Ben-Dor S, Yifa O, Stoler A, Ben-Shlomo I, Bercovich D. Dispersal of an ancient retroposon in the TP53 promoter of Bovidae: phylogeny, novel mechanisms, and potential implications for cow milk persistency. BMC Genomics 2015, 16:53.

65. Melnik BC: Milk: an epigenetic amplifier of FTO-mediated transcription? Implications for Western diseases. J Transl Med 2015, 13:385.

66. Melnik BC, John SM, Carrera-Bastos P, Schmitz G: Milk: a postnatal imprinting system stabilizing FoxP3 expression and regulatory $\mathrm{T}$ cell differentiation. Clin Transl Allergy 2016, 6:18. 
67. Shi C, Zhang M, Tong M, Yang L, Pang L, Chen L, Xu G, Chi X, Hong Q, Ni Y, Ji C, Guo $\mathrm{X}$ : miR-148a is associated with obesity and modulates adipocyte differentiation of mesenchymal stem cells through Wnt signaling. Sci Rep 2015, 5:9930.

68. Li G, Li Y, Li X, Ning X, Li M, Yang G: MicroRNA identity and abundance in developing swine adipose tissue as determined by Solexa sequencing. J Cell Biochem 2011, 112:13181328.

69. Ma J, Jiang Z, He S, Liu Y, Chen L, Long K, Jin L, Jiang A, Zhu L, Wang J, Li M, Li X: Intrinsic features in microRNA transcriptomes link porcine visceral rather than subcutaneous adipose tissues to metabolic risk. PLoS One 2013, 8:e80041.

70. Londoño Gentile T, Lu C, Lodato PM, Tse S, Olejniczak SH, Witze ES, Thompson CB, Wellen KE: DNMT1 is regulated by ATP-citrate lyase and maintains methylation patterns during adipocyte differentiation. Mol Cell Biol 2013, 33:3864-3878.

71. Cho YM, Kim TM, Hun Kim D, Hee Kim D, Jeong SW, Kwon OJ: miR-148a is a downstream effector of X-box-binding protein 1 that silences Wnt10b during adipogenesis of 3T3-L1 cells. Exp Mol Med 2016, 48:e226.

72. Aprelikova O, Palla J, Hibler B, Yu X, Greer YE, Yi M, Stephens R, Maxwell GL, Jazaeri A, Risinger JI, Rubin JS, Niederhuber J. Silencing of miR-148a in cancer-associated fibroblasts results in WNT10B-mediated stimulation of tumor cell motility Oncogene 2013, 32:3246-53.

73. Huang Q, Liu M, Du X, Zhang R, Xue Y, Zhang Y, Zhu W, Li D, Zhao A, Liu Y: Role of p53 in preadipocyte differentiation. Cell Biol Int 2014, 38:1384-1393.

74. Bar Yamin H, Barnea M, Genzer Y, Chapnik N, Froy O: Long-term commercial cow's milk consumption and its effects on metabolic parameters associated with obesity in young mice. Mol Nutr Food Res 2014, 58:1061-1068.

75. Monda KL, Chen GK, Taylor KC, Palmer C, Edwards TL, Lange LA, Ng MC, at all, North KE, Haiman CA. A meta-analysis identifies new loci associated with body mass index in individuals of African ancestry. Nat Genet 2013, 45:690-696.

76. Schwenk RW, Vogel H, Schürmann A. Genetic and epigenetic control of metabolic health. Mol Metab 2013, 2:337-347.

77. Sluijs I, Forouhi NG, Beulens JW, Agnoli C, Arriola L, Balkau B, Barricarte A, at all ; InterAct Consortium. The amount and type of dairy product intake and incident type 2 diabetes: results from the EPIC-InterAct Study. Am J Clin Nutr 2012, 96:382-390.

78. Lee E, Wang J, Yumoto K, Jung Y, Cackowski FC, Decker AM, Li Y, Franceschi RT, Pienta KJ, Taichman RS: DNMT1 regulates epithelial-mesenchymal transition and cancer stem cells, which promotes prostate cancer metastasis. Neoplasia 2016, 18:553- 566

79. Ji J, Sundquist J, Sundquist K. Lactose intolerance and risk of lung, breast and ovarian cancers: aetiological clues from a population-based study in Sweden. Br J Cancer 2015, 112:149-152.

80. Agarwal MM, Rana SV, Mandal AK, Malhotra S, Khandelwal N, Kumar S, Acharya NC, Singh SK. Lactose intolerance in prostate cancer patients: incidence and associated factors. Scand J Gastroenterol 2008, 43:270-276.

81. Desplats P, Spencer B, Coffee E, Patel P, Michael S, Patrick C, Adame A, Rockenstein E, Masliah E: Alpha-synuclein sequesters Dnmt1 from the nucleus: a novel mechanism for epigenetic alterations in Lewy body diseases. J Biol Chem 2011, 286:9031-9037. 
82. Tan YY, Wu L, Zhao ZB, Wang Y, Xiao Q, Liu J, Wang G, Ma JF, Chen SD: Methylation of $\alpha$-synuclein and leucine-rich repeat kinase 2 in leukocyte DNA of Parkinson's disease patients. Parkinsonism Relat Disord 2014, 20:308-313.

83. Funahashi Y, Yoshino Y, Yamazaki K, Mori Y, Mori T, Ozaki Y, Sao T, Ochi S, Iga JI, Ueno SI: DNA methylation changes at SNCA intron 1 in patients with dementia with Lewy bodies. Psychiatry Clin Neurosci 2017, 71:28-35.

84. Chen H, Zhang SM, Hernán MA, Willett WC, Ascherio A. Diet and Parkinson's disease: a potential role of dairy products in men. Ann Neurol. 2002, 52:793-801.

85. Ambros V. The functions of animal microRNAs. Nature 2004, 431:350-355.

86. Wiley AS: Cow milk consumption, insulin-like growth factor-I, and human biology: a life history approach. Am J Hum Biol 2012, 24:130-138.

87. Wiley AS: Does milk make children grow? Relationships between milk consumption and height in NHANES 1999-2002. Am J Hum Biol 2005, 17:425-441.

88. Hoppe C, Mølgaard C, Michaelsen KF: Cow's milk and linear growth in industrialized and developing countries. Annu Rev Nutr 2006, 26:131-173.

89. Yackobovitch-Gavan M, Phillip M, Gat-Yablonski G: How milk and its proteins affect growth, bone health, and weight. Horm Res Paediatr 2017, 88:63-69.

90. Wiley AS: Dairy and milk consumption and child growth: Is BMI involved? An analysis of NHANES 1999-2004. Am J Hum Biol 2010, 22:517-525.

91. Scharf RJ, Demmer RT, DeBoer MD: Longitudinal evaluation of milk type consumed and weight status in preschoolers. Arch Dis Child 2013, 98:335-340.

92. Torfadottir JE, Steingrimsdottir L, Mucci L, Aspelund T, Kasperzyk JL, Olafsson O, Fall K, Tryggvadottir L, Harris TB, Launer L, Jonsson E, Tulinius H, Stampfer M, Adami HO, Gudnason V, Valdimarsdottir UA: Milk intake in early life and risk of advanced prostate cancer. Am J Epidemiol 2012, 175:144-153.

93. Song Y, Chavarro JE, Cao Y, Qiu W, Mucci L, Sesso HD, Stampfer MJ, Giovannucci E, Pollak M, Liu S, Ma J: Whole milk intake is associated with prostate cancer-specific mortality among U.S. male physicians. J Nutr 2013, 143:189-196.

94. Michaëlsson K, Wolk A, Langenskiöld S, Basu S, Warensjö Lemming E, Melhus H, Byberg L: Milk intake and risk of mortality and fractures in women and men: cohort studies. BMJ 2014, 349:g6015.

95. Lu W, Chen H, Niu Y, Wu H, Xia D, Wu Y: Dairy products intake and cancer mortality risk: a meta-analysis of 11 population-based cohort studies. Nutr J 2016, 15:91.

96. Jiang W, Ju C, Jiang H, Zhang D: Dairy foods intake and risk of Parkinson's disease: a dose-response meta-analysis of prospective cohort studies. Eur J Epidemiol 2014, 29:613619.

97. Hughes KC, Gao X, Kim IY, Wang M, Weisskopf MG, Schwarzschild MA, Ascherio A: Intake of dairy foods and risk of Parkinson disease. Neurology 2017, 89:46-52.

98. Samaras TT: Biological parameters explain why shorter or smaller people have lower cardiovascular disease and greater longevity. JSRR 2017, 15:1-16. 